\title{
Green infrastructure in high-rise residential development on steep slopes in city of Vladivostok
}

\author{
Alla Kopeva ${ }^{1 *}$, Olga Ivanova $^{2}$, and Olga Khrapko $^{3}$ \\ ${ }^{1}$ Far Eastern Federal University, 690900, Sukhanova st. 8, Vladivostok, Russia \\ ${ }^{2}$ Vladivostok State University of Economics and Service, 690014, Gogolya St. 41, Vladivostok, \\ Russia \\ ${ }^{3}$ Botanical Garden-Institute of Far Eastern Branch of Russian Academy of Sciences, 690024, \\ Makovskogo st. 142, Vladivostok, Russia
}

\begin{abstract}
The purpose of this study is to identify the facilities of green infrastructure that are able to improve living conditions in an urban environment in high-rise residential apartments buildings on steep slopes in the city of Vladivostok. Based on the analysis of theoretical sources and practices that can be observed in the world, green infrastructure facilities have been identified. These facilities meet the criteria of the sustainable development concept, and can be used in the city of Vladivostok. They include green roofs, green walls, and greening of disturbed slopes. All the existing high-rise apartments buildings situated on steep slopes in the city of Vladivostok, have been studied. It is concluded that green infrastructure is necessary to be used in new projects connected with designing and constructing of residential apartments buildings on steep slopes, as well as when upgrading the projects that have already been implemented. That will help to regulate the ecological characteristics of the sites. The results of the research can become a basis for increasing the sustainability of the habitat, and will facilitate the adoption of decisions in the field of urban design and planning.
\end{abstract}

\section{Introduction}

The authors introduce the hypothesis that innovative facilities of green infrastructure (GI) can be used in high-rise residential apartments buildings on steep slopes in the city of Vladivostok, enhancing the ecological sustainability and aesthetic expressiveness of the urban environment. These facilities include green roofs, green walls, as well as the methods of greening of disturbed hills.

This study introduces a brief conceptual view of the aspects of landscape design in the modern urban environment, including high-rise buildings. A number of theoretical studies are devoted to the integration of nature into urban design and planning. They include the publications of H.L. Venhaus [1], T. Beatley [2-5], the research study of J. Krcmarova that is devoted to E.O. Wilson's concept of biofilia [6]. J. Pomeroy considers skycourts and

\footnotetext{
* Corresponding author: 457594@mail.ru
} 
skygardens in terms of social, cultural, economic, environmental, technological and indirect benefits that they provide to the urban habitat [7].

There are studies devoted to the benefits of nature-based solutions for health and wellbeing. They include a scientific report of Shanahan, Bush \& 5 more authors [8]. Fuller, Irvine \& 3 more have identified the psychological benefits of greenspace [9]. Carrus, Scopellity \& 8 more established the positive effects of biodiversity on the human wellbeing [10]. As Jayasooriya, $\mathrm{Ng} \& 2$ more have found out, Green Infrastructure (GI) practices have shown to be promising in mitigating the air pollution in urban areas of several cities across the world [11]. Shahli, Hussain \& 2 more have figured out that landscape planning and projects that base on the concept of sustainable development assist in creating of a favorable and responsive environment for housing construction [12]. Dobbs, Nitschke and Kendal [13] have studied the landscape structure of 100 cities all over the world, and came to the conclusion that a social system and climate influence the urban landscape and human well-being. Vavilova notes that the solution of the problem of a habitat sustainable development can be achieved with the help of new innovative technological facilities [14].

The experience of using such innovative technological GI facilities as green roofs and green walls in high-rise apartments buildings in many cities all over the world demonstrates that these facilities are widely used. These promising tools are able to significantly improve the urban landscaping. Generalov and Generalova highlight that the process of designing and constructing of high-rise residential apartments buildings in Singapore is based on the principles of sustainable urban development, minimizing the environmental impact [15]. The authors have also identified that a clear standard of comfort for public housing has been developed in the city, including a set of required improvements of the site [16].

Singapore is one of the world's leaders in urban greenery on buildings. In 2009, the National Parks Board of Singapore developed the "Skyrise Greenery Incentive Scheme" (SGIS) [17], and in 2014 the Ministry of the Environment and Water Resources and the Ministry of National Development designed the "Sustainable Singapore Blueprint 2015" [18], which promotes greenery on high-rise buildings, and, thus, contributes towards Singapore's vision of a City in a Garden. Additionally, Skyrise Greenery under the SGIS offers environmental, economic, social and aesthetic benefits. Because of limited land space in Singapore, the SGIS became an important element in sustainable urban development. There are two categories of urban greenery actions funded by the SGIS: the rooftop greenery and vertical greenery on facades and walls of existing and new buildings.

In Singapore, there is a shortage of land to respond to population and economic growth, and a number of authors (Yuen, Hien [19]; Wai [20]) have substantiated the possibility of the existence of gardens on the roofs of public buildings, private houses and other sites not only as the part of urban design, but also as vertical farms that supply residents with food. Despommier [21] and a number of other researchers (Russo, Escobedo \& 2 more [22]) also consider that the vertical farm will have an incredible impact on changing the face of this planet for future generations.

During the last decades several researches were conducted proving that green walls can contribute to enhancing and restoring the urban environment and improving construction building performance. First of all, this is the work of Manso and Castro-Gomes, who presented the review of all types of green wall systems in order to identify and systematize their main characteristics and technologies involved [23].

However, Russia is still behind in adapting the GI facilities mentioned above. Nevertheless, there are works by Russian authors (Khrapko, Kopeva and Ivanova) investigating the application of vertical gardening in the cities of the Russian Far East [24]. Maslovskaya and Chernyavina $[25,26]$ refer to the statistics on the use of flat roofs inThe city of Vladivostok, and consider them as places for social interactions that can increase the 
number of public activity sites. Khusnutdinova, Alexandrova and Novik [27] have determined the most economical vertical green system (VGS), the most user-friendly VGS and the easiest to implement VGS in the conditions of St. Petersburg.

The situation with the adaptation of GI facilities is complicated by the location of highrise residential apartments buildings on steep slopes. Improper planning and rapid development in the management of high-rise construction on steep hills often leads to the destruction of natural elements and the loss of green space. The assortment of plants for greening of disturbed steep slopes has not been sufficiently studied. In this regard, the work of Chinese researchers Chau and Chu [28] is very interesting. They have identified that the fern cover can reduce soil erosion on steep slopes.

\section{Materials and Methods}

The city of Vladivostok is the administrative, economic and cultural center of the Primorsky Krai, the core of the largest agglomeration in the settlement system of the Far East, the most important center of the Pacific regional settlement system. The authors examined all sites of high-rise residential apartments buildings that have been constructed in the city of Vladivostok after 2000. The city is located in the southern part of Primorsky Krai. The Amur and Ussuri Bays that are part of the Peter the Great Bay of the Sea of Japan wash it. The study examined the territory of the city within the boundaries of the Muravyov-Amursky Peninsula. The following materials have become the theoretical basis for the study:

- Data on the analysis of hill slope and orientation maps in the city of Vladivostok (2004) [29];

- Data on the current state of the territory, found in the Master Plan of the city of Vladivostok Municipal District, designed by the Primorgrajdanproekt project organization until 2025 (2012);

- Data on the conditions of nature on the territory of the city of Vladivostok urban district, provided in the report of the Pacific Institute of Geography of the Far Eastern Branch of the Russian Academy of Sciences titled as Integrated assessment of the territory of the city of Vladivostok and agglomeration (2012).

In accordance with SR 131.13330.2012, the climate of the city of Vladivostok urban district is a moderate monsoon. The relief is low-mountainous, strongly dissected with absolute elevations of 250-350 m, with separately rising domed mountain peaks $430-475 \mathrm{~m}$ high. The relief of the city has a shallow structural module, with small areas of homogeneous slope and orientation characteristics. The city of Vladivostok area is seismically active with the possible force of earthquakes reaching 6-7 points (according to SR 14.13330.2014). The city's territory can be exposed to dangerous natural and man-made impacts, causing emergency situations. The dangerous natural phenomena occurring in the city include periodic tropical cyclones (typhoons). Tsunamis and earthquakes are not excluded.

In Russia, high-rise buildings are denoted as those that are taller than $75 \mathrm{~m}$ (starting from 25 floors) [30]. High-rise buildings on the steep of the city of Vladivostok slopes are located on high stylobates, therefore, this study has considered sites with high-rise residential apartment buildings of 18 to 52 floors. The sites for the research were symbolically divided into two groups: set in operation and under construction. In the first group, 27 sites were examined. The second group has 36 sites.

In the process of research, the photos of high-rise residential buildings were made, the slope of the territory and orientation of the hills were determined, microclimatic conditions were examined, aesthetic and ecological characteristics were described, and federal and local regulations concerning urban landscaping were analyzed. In order to determine the 
range of plants for the greening of high-rise apartments buildings on the slopes, the authors conducted an introductory experiment at the Laboratory of Far Eastern Flora of the Botanical Garden Institute of the Far Eastern Branch of the Russian Academy of Sciences.

Based on the data obtained, it was suggested that the percentage of green areas of the high-rise residential construction sites in the city of Vladivostok does not meet regulatory requirements, the original natural elements such as relief and landscapes are not preserved, they are disturbed in the process of construction. The first bases concerning the necessity to solve the problem of high-rise building greening on the steep slopes of the city of Vladivostok were presented by the authors in previous works [31, 32, 33].

\section{Results}

The authors investigated the conditions of all high-rise residential sites in the city of Vladivostok It has been identified that the majority of high-rise residential sites are located in the central part of the city of Vladivostok on slopes up to $30 \%$ at the top elevations of the relief (figure 1).

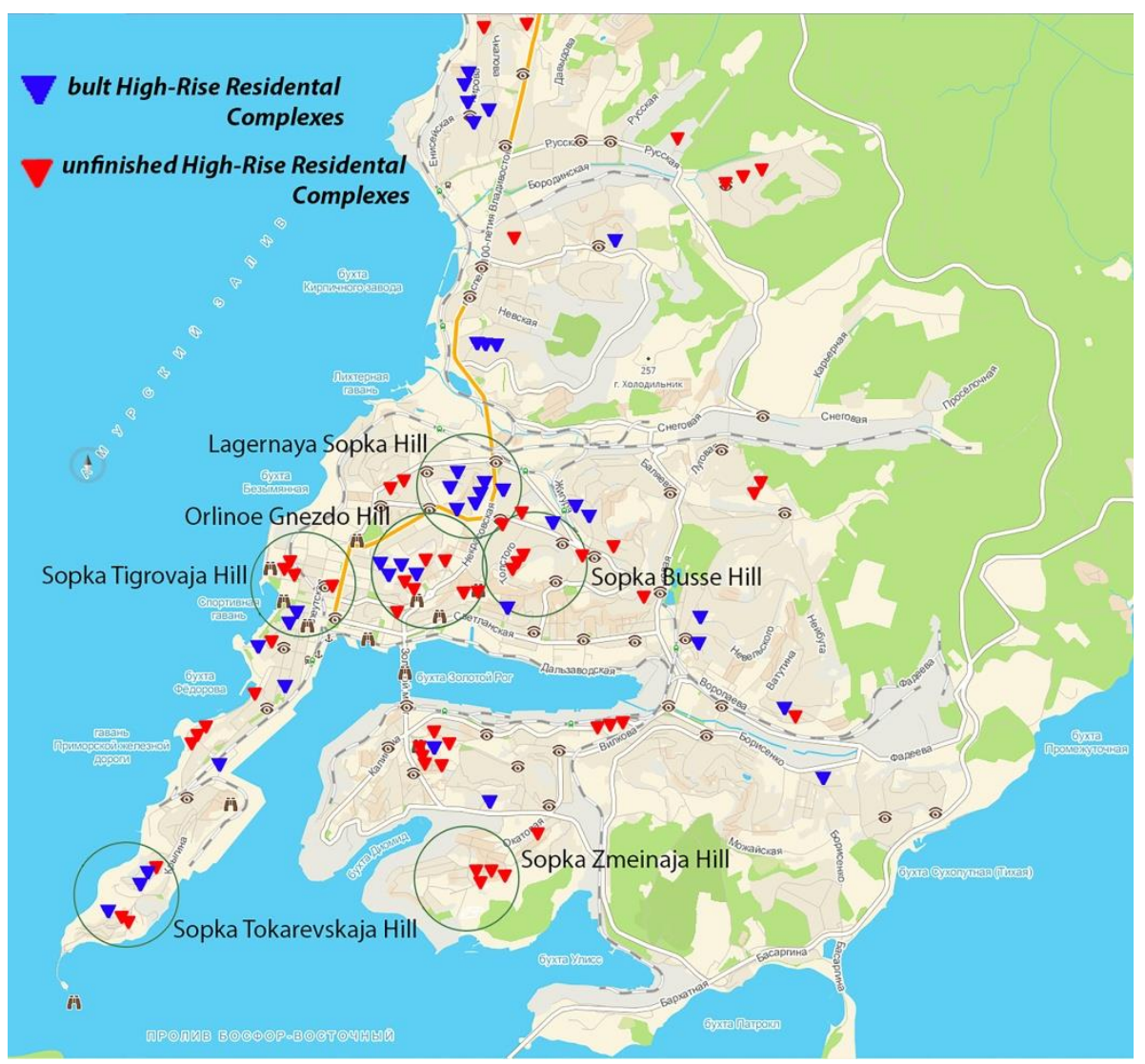

Fig.1. Layout of high-rise residential complexes in the city of Vladivostok

The reasons why the initial natural relief is damaged on these territories have been indicated as the following: a large structural module of construction does not correspond to a small structural module of a relief; the application of construction methods that are used in building on flat relief (figure 2). 
a
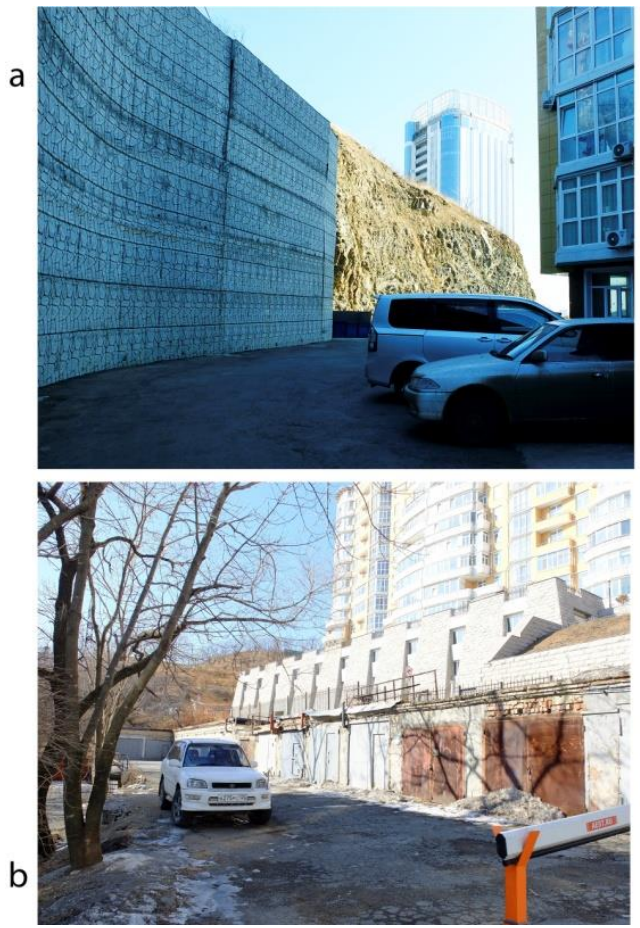
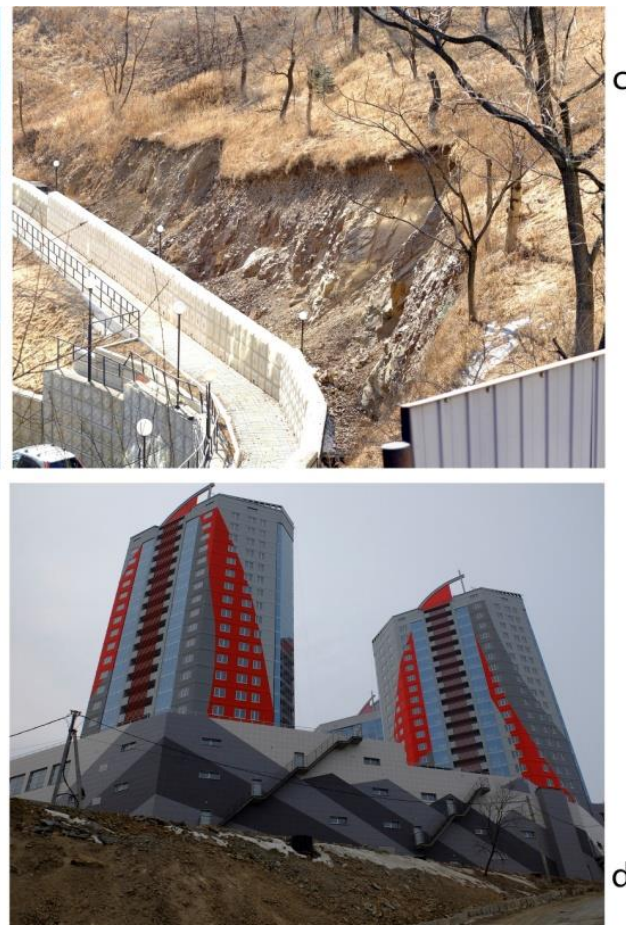

Fig.2. Examples of high rise residential complexes construction on the slopes in the city of Vladivostok: a - Kaskad, b - Orlinoe Gnezdo-I, c - Orlinoe Gnezdo-II, d - Alye Parusa

The reasons why the regulatory requirements for greening of high-rise residential sites on steep hills are not observed have been identified as the following: the failure to comply federal and local construction rules with the features of steep slopes greening - the current standards do not consider green roofs and green walls as a landscaping facility of compensatory nature; the disturbance of the relief leads to the disturbance of soil cover on dumps and slopes, the destruction of primary plant groupings, the changes in the dynamics of plant communities. Single examples of the use of green roofs have been identified (figure 3).

a
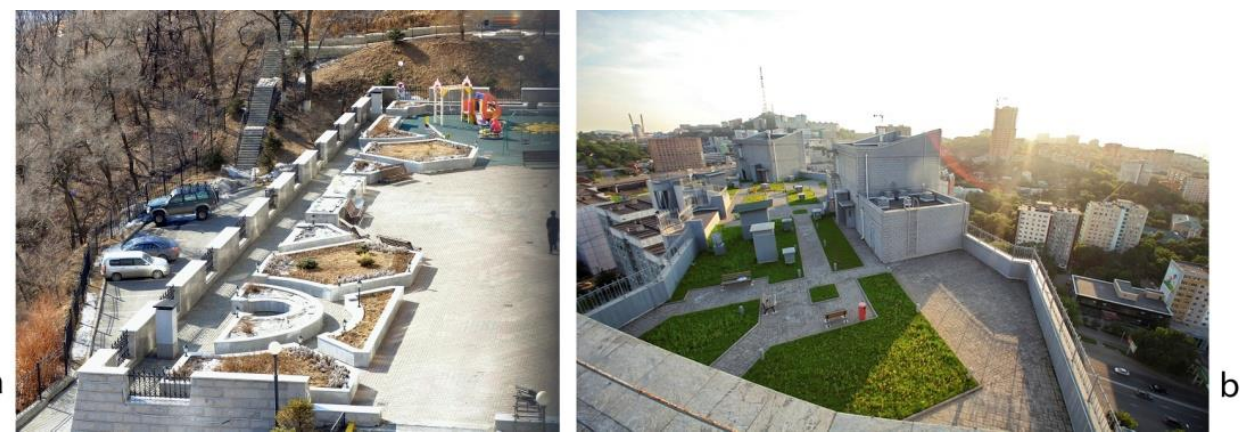

Fig.3. Examples of area landscaping of high-rise residential apartment buildings in the city of Vladivostok: a - Orlinoe Gnezdo-I, b - Armada

Examples of the use of green walls and slope greening are absent. Proposals on the use of GI facilities in high-rise residential sites on steep slopes in the city of Vladivostok have been formulated and the first proposals on the assortment of plants have been given. 


\section{Discussion}

\subsection{Theoretical studies of GI facilities implementation}

A review of previous studies, journals and documents provides a theoretical justification for the importance of applying innovative GI facilities as elements of landscape design to replace the original natural environment in dense high-rise residential sites on steep slopes. This study is based on research materials and documents on the integration of nature into urban design and planning [1-7]; the benefits of nature-based solutions for health and wellbeing [8-11]; the importance of landscape design in the formation of a stable habitat [1213]; the solution of the problem of ecologization and humanization of the environment [14]; the results of using GI facilities in dense high-rise sites [17, 18], including the foreign experience of using green roofs, vertical trusses [19-22] and vertical green systems (VGS) $[15,16,23]$, as well as Russian experience of using GI facilities [24-27] and the experience of restoration of disturbed landscapes [28].

\subsection{The practice of high-rise residential construction on the city of Vladivostok slopes}

There is a unique practice of high-rise residential construction on the city of Vladivostok slopes. It supports the image of the Primorsky Krai capital as the Russian Pacific Gate, and preserves the peculiarity of its seaside landscape.

For a long time, high-rise construction was banned in the city of Vladivostok due to seismic hazard. In recent years, high-rise residential apartments buildings are being built, and this tendency will continue due to such reasons as the high price of land and its deficit, the economic attractiveness for investors and developers, the continuing demand for housing, and the willingness of the authorities to accept and approve such projects. There are other reasons why high-rise construction will continue. Firstly, after the construction of the Zolotoy Bridge (length - 1400 meters, width - 30 meters, desk level above the water level - 65 meters, height of the pylons - 230 meters), the view of the central part of the city has significantly changed. Giant bridge requires noticeable buildings on nearby hills. Secondly, according to the current land use and construction plans, almost all the city of Vladivostok refers to the zone of high-rise buildings. This means that the whole city can be built up with high-rise apartments buildings.

In 1997, the first 25-storey high-rise residential apartment building of a monolithic structure, 80.5 meters high, was built at Fastovskaya Street. The next high-rise residential complexes in the city of Vladivostok appeared in the first decade of the XXI century: 2006 - Atlantis-I, 2007 - Arcade House. In 2010-2013, there was a significant increase in the construction of high-rise apartments buildings. During this period, most of the high-rise residential complexes were built. The largest of them are: Metallist 5 (2010), six residential complexes in the residential district Snegovaya Pad (2011), Admiral (2012), Pallada (2012). The city administration plans to continue the construction of high-rise residential apartments buildings. Currently, dozens of projects have been approved, and the construction of new buildings has already begun with the completion dates planned in 2017-2020: Alye Parusa, Atlantix, Zolotoy Rog, Magnum, etc.

Until the 2000s, the upper parts of the city of Vladivostok slopes were not built up. Multi-apartment houses up to 16 floors were located along the relief, along the slopes, encircling them and leaving its upper part with a natural landscape. At the moment, the slopes of all the hills located in the central part of the city of Vladivostok are built up: Sopka Orlinoe Gnezdo (143 m), Sopka Tigrovaja (79 m), Sopka Busse (206 m), Sopka Burachek $(138 \mathrm{~m})$ and others. All the hills have a rocky base, and were originally covered 
by local plants. The relief in the central part of the city has slopes of up to $30 \%$, in some areas it is up to $60 \%$ [29].

The authors examined all high-rise residential sites that have been constructed in the city of Vladivostok after 2000. The authors identified that high-rise buildings destroy the unique natural landscape of the city of Vladivostok. There is a negative impact of new high-rise apartment buildings on the local areas. As the scale of modern construction in the city of Vladivostok is comparable to the scale of the hills, the new buildings dramatically change the wind and insolation regime. Those locations that used to be sunny and warm are now covered with shadow and blown with the wind due to high-rise apartment buildings. According to the laws of aerodynamics, the elite high-rise residential buildings in the area of Sopka Orlinoe Gnezdo hill redirect the north and south winds from the upper floors down to pedestrians.

The authors figured out that due to large deviations of the relief with some slopes reaching up to $30 \%$ or more, the problem of disturbing the natural relief and its further transformation into anthropogenic one is acute. In the central part of the city, the retaining walls transform high-rise building adjacent territories into non-aesthetic and inhuman stone landscape, free from plants.

\subsection{Greening of high-rise residential sites on steep slopes in the city of Vladivostok}

The reason why the regulatory requirements for greening of high-rise residential sites on steep slopes in the city of Vladivostok are not universally observed, have been identified: the failure to comply federal and local construction rules with the features of steep slope greening. The current standards do not consider green roofs and green walls as a landscaping facility of compensatory nature. According to SR 42.13330.2011, where federal norms are specified, the area of green roofs should not be included in the indicator of the territory green space when calculating the balance of the area of the projected site, while the area of the exterior surfaces of buildings and constructions for vertical gardening should be indicated in the "Accomplishment" section. This requirement corresponds to construction works on flat relief, but not on steep slopes. It is impossible to plant trees and shrubs in a traditional manner on steep slopes due to the lack of free horizontal areas in the ground level. Therefore, the use of green roofs and green walls is a necessity.

According to the current land use and construction plans for the city of Vladivostok, the area of the building site is determined in accordance with SR 30-11-98: the minimum area of the multi-apartment residential building is calculated at the rate of 17.3 sq.m. per person in case of the compaction of the existing building and 11.7 sq.m. per person in the projected building. The area of green territory should be at least 5 sq.m. per person. It is impossible to comply with these standards on dense high-rise sites on steep slopes in the central part of the city.

The favorable location of a building in the city center forces developers to apply to the city authorities for declining the percentage of green areas, or include play and sports grounds, parking lots, green roofs and vertical gardening as their part. In existing conditions, when creating green roofs and vertical landscaping, mobile greening is used, namely growing plants in special mobile containers.

Modern methods of construction and technology do not allow preserving the original natural relief and greening on steep slopes. A building can be inscribed in the existing relief only when erecting a stylobate with a height of 5-6 floors. This entails extensive work on excavating the soil, erecting retaining walls and strengthening slopes. The broken relief is strengthened with the help of gabions, geo-grids, non-woven geo-textiles, prefabricated concrete-lawn elements in combination with greening. It has been identified that while 
constructing high-rise apartments buildings in the city of Vladivostok, trees are cut down and the fertile soil is replaced with a clay substrate. Steep hills are either filled up with soil unsuitable for growing plant, or are filled up with fertile soil without preliminary preparation. The root system of bushes and lawn grass does not retain soil, therefore slopes are eroded. As a rule, construction companies leave slopes without greening in the hope that nature will take care of them, and they will cover themselves with green plants.

The authors of the study conducted an introductory experiment in the Laboratory of Far Eastern Flora of the Botanical Garden Institute of the Far Eastern Branch of the Russian Academy of Sciences. The experiment demonstrated the first results in determining the range of plants for the greening of high-rise areas on the slopes. Local perennials and shrubs are at the top of the list for planting roofs, while the key part of the list for vertical landscaping and slope greening are vines as Far Eastern and introduced species and forms.

\section{Conclusion}

Currently, there is an increase in the rates of environmental degradation and a reduction in the area of gardening in areas of high-rise residential sites on steep slopes in the city of Vladivostok. It is caused by the application of construction methods that are suitable for building on flat relief, but when applied on steep relief they lead to its disturbance, the disappearance of the original natural elements of gardening, and ultimately to the deterioration of the ecological situation and the dehumanization of the habitat. Taking this into account, the use of GI facilities such as green roofs, green walls and slope greening is necessary. Further research is recommended to develop plant assortments for green roofs, green walls and slope greening, taking natural and climatic conditions of the city of Vladivostok into account. The results of this study can support local policies aimed at providing green space for all residents of the city.

\section{References}

1. H. L. Venhaus. Designing the Sustainable Site: Integrated Design Strategies for Small Scale Sites and Residential Landscapes 256 (Publisher Wiley, 2012)

2. T. Beatley. Biophilic Cities: Integrating Nature into Urban Design and Planning 208 (Publisher Island Press, 2010)

3. T. Beatley, L. Laurian, D. Medearis, W. Daseking, M. Bruel, M. Jaakkola, M. Moretti, L. A. Orive, R. D. Lema, C. Ween. Green Cities of Europe: Global Lessons on Green Urbanism 248 (Publisher Island Press, 2012)

4. http:// www.mdpi.com/journal/sustainability (last accessed 21.03.2017)

5. T. Beatley. Handbook of Biophilic City Planning \& Design 312 (Publisher Island Press, 2017)

6. J. Krcmarova, E.O. Wilson's concept of biofilia and the environmental movement. Klaudyan: Int. J. of Historical Geography and Environmental History 6/1-2, 4-17 (2009)

7. J. Pomeroy. The Skycourt and Skygarden: Greening the urban habitat. Publisher: Routledge, 304 p. (2014)

8. https://www.nature.com/articles/srep28551 (last accessed 20.03.2017)

9. http://rsbl.royalsocietypublishing.org/content/3/4/390.figures-only (last accessed 21.03.2017) 
10. http://www.sciencedirect.com/science/article/pii/S0169204614002552 (last accessed 21.03.2017)

11. V. M. Jayasooriya, A.W.M Ng, S. Muthukumaran, B. J. C. Perera, Green infrastructure practices for improvement of urban air quality Urban Forestry \& Urban Greening 21, 34-47 (2017)

12. F. M. Shahli, M. R. M. Hussain, I. Tukiman, N. Zaidin, The Importance Aspects of Landscape Design on Housing Development in Urban Areas APCBEE Procedia 10, 311-315 (2014)

13. C. Dobbs, C. Nitschke, D. Kendal, Assessing the drivers shaping global patterns of urban vegetation landscape structure Science of The Total Environment 592 pp 171177 (2017)

14. T Ya Vavilova, Retrospective review of UN documents on sustainable development of the living environment Vestnik SGASU. Town Planning and Architecture 1, 24-28 (2011)

15. E. M. Generalova, V. P. Generalov, Designing high-rise housing: The Singapore experience CTBUH journal 4, 40-45 (2014)

16. E. M. Generalova, V. P. Generalov, N. D. Potienko, Affordable housing under shaping dense vertical urbanism, Cities to Megacities. Shaping Dense Vertical Urbanism Proceedings of the CTBUH 2016. Council on Tall Buildings and Urban Habitat, Chicago, 650-659 (2016)

17. https://www.skyrisegreenery.com (last accessed 12.03.2017)

18. http://www.mewr.gov.sg/ssb/files/ssb2015.pdf (last accessed 12.03.2017)

19. B. Yuen, W.N. Hien. Resident perceptions and expectations of rooftop gardens in Singapore Landscape and Urban Planning, 73/4, 263-276 (2005)

20. W. T. D. Wai. Beyond Skyrise Gardens: The Potential of Urban Roof Top Farming in Singapore, CTBUH research Paper, 412-427 (2011)

21. D. Despommier. The Vertical Farm: Feeding the World in the 21st Century, 336 (Publisher Picador, 2011).

22. A. Russo, F. J. Escobedo, G. T. Cirella, S. Zerbe. Edible green infrastructures: An approach and review of provisioning ecosystems services and disservices in urban environment. Agriculture, Ecosystems and Environment, 242, 53-66 (2017)

23. M. Manso, J. Castro-Gomes, Green wall systems: A review of their characteristic, Renewable and Sustainable Energy Reviews, 41, 863-871 (2015)

24. O. V. Khrapko, A. V. Kopeva, O. G. Ivanova, Vertical green walls as an element of landscape design The New Ideas of New Century-2016 - The Sixteenth International Scientific Conference Proceedings 3, 159-163 (Khabarovsk, 2016)

25. O. V. Maslovskaya, L.A. Chernyavina. Special features of functioning of flat roofs as the places for social communication (on the example of VSUES campus in the city of Vladivostok), Sociology of City 4, 53-67 (2014)

26. http://elibrary.ru/item.asp?id=24921741, pdf. (last accessed 28.03.2017)

27. A. I. Khusnutdinova, O. P. Aleksandrova, A. N. Novik, Vertical greenery systems, Construction of unique buildings and structures, 12(51), 20-32 (St. Petersburg, 2016)

28. N. L. Chau, L. M Chu. Fern cover and the importance of plant traits in reducing erosion on steep soil slopes, CATENA, 151, 98-106 (2017)

29. http://elibrary.ru/item.asp?id=24507861, pdf. (last accessed 25.03.2017) 
30. V. P. Generalov, E. M. Generalova. Problems in the classification of high-rise residential buildings, Urban planning and architecture, 2, 12-14 (2011)

31. O. V. Khrapko, A. V. Kopeva. Prerequisites for the formation of the concept of landscaping of the city of Vladivostok, Problems of landscaping of settlements Materials of the scientific-practical conf. 149-156 (2013)

32. O. V. Khrapko, A. V. Kopeva, M. N. Koldaeva, E. N. Golovan Informal style in landscape architecture of Far-Eastern cities, The New Ideas of New Century-2013 The Thirteenth Int. Scientific Conf. Proc. 3, 395-399 (2013).

33. http://elibrary.ru/item.asp?id=24848604, pdf. (last accessed 28.03.2017) 